\title{
INDIGENOUS LANGUAGE
}

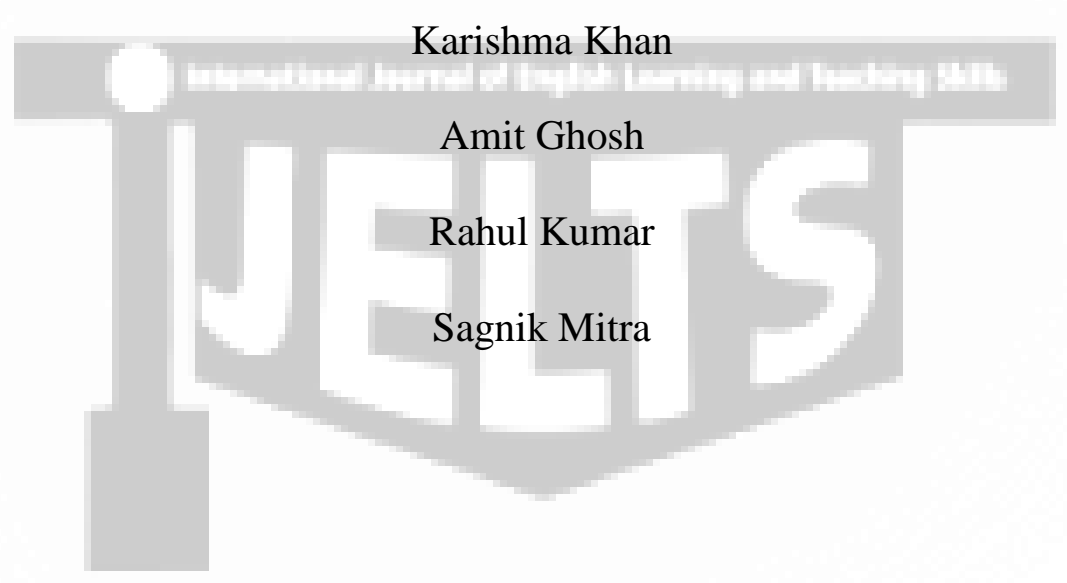




\section{INDIGENOUS LANGUAGE}

\section{Introduction}

An indigenous language or autochthonous language is a language that is native to a region and spoken by indigenous people. This language is from a linguistically distinct community that originated in the area. Indigenous languages are not necessarily national languages and national languages are not necessarily indigenous to the country. Many indigenous peoples worldwide have stopped passing on their ancestral languages to the next generation and have instead adopted the majority language as part of their acculturation into the majority culture.

At present, 96 per cent of the world ${ }^{\text {ee }}$ approximately 6,700 languages are spoken by only 3 per cent of the world ${ }^{\text {ee }}$ p population. Although indigenous peoples make up less than $6 \%$ of the global population, they speak more than 4,000 of the world ${ }^{\text {ee }}$ languages. Conservative estimates suggest that more than half of the world"e s languages will become extinct by 2100 . Other calculations predict that up to 95 per cent of the world see languages may become extinct or seriously endangered by the end of this century. The majority of the languages that are under threat are indigenous languages. It is estimated that one indigenous language dies every two weeks.

Estimate that there are about 6,000-7,000 different languages spoken in the world today. The imprecision in this estimate is largely due to the fact that some dialects are in the process of diverging and it is not clear that they have reached the stage of being separate languages. There are about 200 languages that have a million or more native speakers. Mandarin 
Chinese is the most common, being spoken by around $874,000,000$ people as a native language. English is a distant third with approximately $341,000,000$ native speakers. English is far more worldwide in its distribution than all other spoken languages. It is an official language in 52 countries as well as many small colonies and territories. In addition, 1/4 to $1 / 3$ of the people in the world understands and speaks English to some degree. It has become the most useful language to learn for international travel.

In reality, the distribution of languages globally is very complex and difficult to easily describe. Numerous migrations of people over the last several centuries have resulted in most large nations now having many different languages. There are at least 165 languages spoken in the United States today. Consequently, it is somewhat misleading to describe the U.S. as being an English speaking country. The same caution applies to other multicultural nations as well.

\section{INDIGENOUS YEAR OF INTERNATIONAL LANGUAGES 2019}

According to 1st January, 2019 International Year of Indigenous Languages it is observed that 7 thousand languages spoken worldwide, 370 million indigenous people in the world, 90 countries with indigenous community, 5 thousand different indigenous culture, 2680 languages are in danger.

The International Year of Indigenous Languages is a United Nations observance in 2019 that aims to raise awareness of the consequences of the endangerment of Indigenous languages across the world, with an aim to establish a link between language, development, peace, and reconciliation. 


\begin{abstract}
AIMS
The International Year of Indigenous Languages aims to focus attention on the risks confronting indigenous languages, especially those significant for development, reconciliation, good governance and peace building. It aims to improve quality of life, wider international cooperation and visibility and strengthened intercultural dialogue to reaffirm the continuity of indigenous languages and cultures.

The year plans to carry out activities which will take form in the following three thematic areas, Supporting the revitalization and maintenance of indigenous languages through: creation of more materials and content and a wider range of services, using language, information and communications technologies (Support) Preserving indigenous languages, creating access to education, information and knowledge in and about indigenous languages for indigenous children, young people and adults, improving the data collection and sharing of information (Access)

Mainstreaming the knowledge areas and values of indigenous peoples and cultures wit hin broader sociocultural, economic and political domains, as well as cultural practices such as traditional sports and games (Promotion).
\end{abstract}

\title{
The year has five main intervention areas:
}

a. Increasing understanding, reconciliation and international cooperation.

b. Creation of favorable conditions for knowledge-sharing and dissemination of good practices with regard to indigenous languages.

c. Integration of indigenous languages into standard-setting. 
d. Empowerment through capacity-building.

e. Growth and development through elaboration of new knowledge.

\section{Disappearance}

Some indigenous languages are disappearing for various reasons, including the mass extinction of entire speaker communities by natural disaster or genocide, aging communities where the language is not passed on, and oppressive language planning policies that actively seek to eradicate language. In North America, since 1600, at least 52 Native American languages have disappeared. Globally, there may be more than 7,000 languages that exist in the world today, though many of them have not been recorded because they belong to tribes in rural areas of the world or are not easily accessible. It is estimated that 6,809 "living" languages exist in the world today, with $90 \%$ having fewer than 100,000 speakers. This means that roughly 6,100 languages are facing a risk of eventual extinction. Some languages are very close to disappearing.

Forty six languages are known to have just one native speaker while 357 languages have fewer than 50 speakers. Rare languages are more likely to show evidence of decline than more common ones.

Oklahoma provides the backdrop for an example of language loss in the developed world. It boasts the highest density of indigenous languages in the United States. This includes languages originally spoken in the region, as well as those of Native American tribes from other areas that were forcibly relocated onto reservations there. The U.S. government drove the Yuchi from Tennessee to Oklahoma in the early 19th century. Until the early 20th century, most Yuchi tribe members spoke the language fluently. Then, government boarding schools severely punished American Indian students who were overheard speaking their own 
language. To avoid beatings and other punishments, Yuchi, and other Indian children abandoned their native languages in favor of English.

Other tribes of Native Americans were also forced into government schools and reservations. They were also treated badly if they did not become "civilized". This meant they were to go to Christian churches and speak English. They were forced to give up their tribal religious beliefs and languages. Now, these Native Americans are trying to regain some of their lost heritage. They gather at "Pow-wow" to share culture, stories, remedies, dances, music, rhythms, recipes and heritage with anyone who wants to learn them.

In January 2008, in Anchorage, Alaska, friends and relatives gathered to bid their last farewell to 89 year old Marie Smith Jones, a beloved matriarch of her community. "As they bid her farewell to her, they also bid farewell to the Eyak Language as Marie was the last fluent speaker of the language."

In the Isle of Man, following the decline in the use of Manx during the 19th century, Yn Cheshaght Ghailckagh (The Manx Language Society) was founded in 1899. By the middle of the 20 th century only a few elderly native speakers remained (the last of them, Ned Maddrell, died on 27 December 1974), but by then a scholarly revival had begun to spread and many people had learned Manx as a second language. The revival of Manx has been aided by the recording work done in the 20th century by researchers.

\section{PRESERVATION OF INDIGENOUS LANGUAGE}

Language is an essential aspect of cultural identity globally. According to UNESCO: "Languages, with their complex implications for identity, communication, social integration, education and development, are of strategic importance for people and the planet. There is growing awareness that languages play a vital role in development, not only in ensuring 
cultural diversity and intercultural dialogue, but also in attaining quality education for all and strengthening cooperation, in building inclusive knowledge societies and preserving cultural heritage, and in mobilizing political will for applying the benefits of science and technology to sustainable development."

Through various projects, UNESCO supports the preservation of language diversity.

\section{CASE STUDY: How Sanskrit has become extinct in India from Public life}

Sanskrit declined after it ceased to be a medium of knowledge production in medieval era. Learning is the first step to resuscitate the language. But one doubts if it was made for a competitive environment.

National Sanskrit day is observed annually on Shravan Purnima, which coincides with Raksha Bandhan. Observances are extended to a full week called the national Sanskrit week. This year it is being observed from August 4 to 10 inclusive of the Sanskrit day on August 7. Its purpose is to promote and popularize the use of Sanskrit.

There is dichotomy about that classical language. It remains a popular subject at higher secondary, graduation and post-graduation level. The only other place it exists outside the curricula is Hindu religious ceremonies (karma kanda) like pujas, marriages and shraddhs etc. But otherwise there is practically no journalism; no modern literature; no film industry; no television channel or music industry in the language.

It is strange how Sanskrit disappeared from public life after dominating philosophic, literary and artistic discourses in India for ages. Sanskrit experts themselves are clueless about it. They generally attribute it to external factors like educational policies of Lord Thomas Babington Macaulay and Jawaharlal Nehruees unwillingness to declare it as national language. 
To blame the education policies of the British is politically correct. To blame the Muslim rule entails some risk from its overzealous supporters in India. But to analyze one ees historical self is the most difficult task. Like it or loathe it, Sanskrit scholars will have to exercise the third option if they wish to understand the plight of the godly language.

Currently they are banking on the classical greatness of Sanskrit to assert its superiority. They argue that Sanskrit is a scientific tongue, mother of most Indian languages and rich in spiritual and temporal literature. Nobody ever denies that claim.

But the question remains why Sanskrites achievement in the last millennium fell utterly short of its achievements in earlier millennia. Sanskrit got marginalized in public domain after it ceased to be a medium of knowledge production in the medieval era. This was the principal reason for its decline.

It was the growth of vernaculars in the medieval ages that dented Sanskrit"s prospects. Many of those vernaculars arose from Sanskrit, and held its legacy in high esteem. But they wished to cater to the masses, and soon assumed a life of their own. The Bhakti movement went hand in hand with vernacular languages. Vernacular movement was started by Kabir in north India, Sant Dnyaneshwar in Maharashtra, Vidyapati in Mithila and Chandidas in West Bengal. Goswami Tulsidas — himself adept in Sanskrit — chose to write his Ramcharitmanas in Awadhi in the 16th century.

Sanskrit pundits of Varanasi tried to stall the project, alleging that Ramayan would be denigrated if rendered into non-Sanskrit language. But Madhusudana Sarasvati, the great Vedantist monk, came to his rescue. Madhusudana Sarasvati, being a Bengali, he knew Ramayan could well be written in a non-Sanskrit language. Tulsidase century saw the rise of other poets writing in dialects of Hindi — Surdas, Abdul Rahim Khan-I-Khana (who wrote in Awadhi, Sanskrit and Persian), Raskhan, Keshavdas (himself a Sanskrit 
scholar) and Biharilal Chaube. Interestingly Madhusudana Sarasvati, author of Advaita Siddhi, was the last person in India who became a public persona by writing solely in Sanskrit.

After him none, including Swami Dayananda Saraswati and Sant Thyagaraja could excel in public life solely through Sanskrit.

But the essential problem with medieval era in India was dearth of knowledge production. There were literary creations but no scientific or political knowledge production that could lead India to modernity. The archaic knowledge bank still remained with Sanskrit without being challenged by vernaculars. But the advent of English in the early 19th century changed the game. English brought new knowledge pattern that was founded on contemporary information, research, investigation and rationality. It believed in making knowledge a ,laboratory ${ }^{e e}$ rather than ,templee. Sanskrit did not have the wherewithal to demystify this new politico-legal-technological regime. Several stalwarts of that era from Raja Ram Mohan Roy to Madan Mohan Malaviya had sound knowledge of Sanskrit. But they chose to write and speak in English or their mother tongue. It is a myth that British ,imposed"e English on India that led to the decimation of Sanskrit. Had the British ,imposed ${ }^{\text {ee }}$ English, then vernaculars of India would have also suffered a similar fate. But what explains the rapid growth of vernacular (now called modern Indian languages) literature under the same British rule.

Why Sanskrit failed to produce a Bankim Chandra Chattopadhyay, Rabindranath Tagore, Bharatendu Harishchandra, Subramania Bharati, Utkalmani Gopabandhu Das etc. This is a question that Sanskrit exponents should ask themselves rather than invent an excuse. The truth is that in the British period, Sanskrit underwent a „Renaissance ${ }^{e e}$ From Warren Hastings (1772) to Lord Amherst (1828) the British pursued a policy of „orientalisme 
whereby Sanskrit, Persian, Urdu etc were promoted. As a part of this project Sanskrit College of Varanasi (now Sampurnanand University), Calcutta Sanskrit College etc were founded. Devnagri font was developed leading to printing of Sanskrit manuscripts.

Many lost Sanskrit manuscripts were recovered from various parts of India; and translation work was undertaken. Even after the victory of the Anglicists, represented by Macaulay, Sanskrit did not lose out. No Sanskrit college or Sanskrit pathshala was closed down. In 1902 Swami Shraddhanand started Gurukul Kangri near Haridwar. Madras Sanskrit College was founded in 1906.

It was the growth of modern Indian languages that foreclosed the chances of Sanskrit.

Sanskrit" s primacy belonged to an era when books were not mass produced. But in the 19th and 20th centuries, when books began to be mass produced, there emerged a commercial relationship between writer, publisher, printer, book seller and reader. Sanskrit lost out. When in ancient time a Bhartihari, Bhasa or Bharavi wrote a work, it was not their intention that maximum people should possess copy of their work. But sales figure became an important component of literature in modern period.

Thus Sanskrit, with its small readership base, could not compete. The same is true of viewership and audience. That is why Sanskrit got confined to Sanskrit teaching and learning in the 20th century. Both the Sanskrit commissions in independent India $(1957,2015)$ dealt with only that aspect of Sanskrit. Learning is definitely the first step to resuscitate the great language. But one doubts whether Sanskrit was made for a competitive environment.

\section{Conclusion}

The issue regarding the significance of language in various social movements has been widely discussed in both the academic literature and the media. The role of language in 
indigenous culture deserves special attention because language and culture are two interrelated things. Actually, the concept of culture refers to "knowledge, experience, meanings, beliefs, values, attitudes, and religions, concepts of self, the universe and selfuniverse, relationships, hierarchies of status, role expectations, spatial relations, and time concepts" collected and utilized by a particular group of people over many generations. In other words culture is reflected in various language patterns, influencing the process of communication. Indigenous culture involves a set of activities that are deeply rooted in the past. Besides, "indigenous culture affects the development of language," promoting science knowledge and social growth. Because of the rapid decline in language diversity of indigenous people, there is the considerable decline in cultural diversity. Undoubtedly, these changes are caused by historical developments, such as imperialism and colonialism, intensive global economic development, and the growth of militarism. Besides, cultural beliefs affect the use of language by indigenous peoples. Language plays an important role in indigenous culture as it is part of culture and cannot exist without culture. 